\section{Estudio genealógico del linfedema de las extremidades inferiores en una zona con filariasis endémica}

A pesar de que la infestación por el gusano adulto de la filaria Wuchereria bancrofti puede causar linfangiectasia, la mayoría de las personas infestadas permanecen clínicamente asintomáticas durante largo tiempo. En muchos casos, la infestación ocasiona linfedema de las extremidades inferiores, especialmente en mujeres. Algunos autores opinan que una parte de la población expuesta a la infestación por filarias podría estar predispuesta genéticamente a sufrir linfedema, pero la información reunida hasta el momento se basa en investigaciones inmunológicas. Nunca se ha evaluado adecuadamente la influencia de factores genéticos en la susceptibilidad a este trastorno.

En este estudio genealógico se evaluó la presencia de linfedema producido por filarias en una comunidad rural endémica de Haití con el objetivo de investigar el nivel de agregación del trastorno y determinar si su frecuencia era mayor entre los familiares de pacientes con linfedema que en la población en general.

En la investigación participaron 368 mujeres de 16 años de edad o mayores que recibieron tratamiento para el linfedema de los miembros inferiores en la clínica del Hôpital Ste. Croix, en Leogane, Haití, entre junio de 1995 y diciembre de 1999. Como casos índice del estudio se seleccionó a las 172 pacientes que habían sido el primer caso de linfedema en sus respectivas familias. Entre septiembre de 1998 y diciembre de 1999 se recolectó información detallada sobre los familiares de los casos índice mediante entrevistas domiciliarias. Nadie se negó a responder a la encuesta. La edad de los casos índice varió de 16 a 81 años (media: 40,9 años; mediana: 41 años).

Se estudió a 2235 familiares de los casos índice, sin criterios restrictivos en cuanto a la edad. El número de miembros de cada familia (familiares de primer grado, medios hermanos e hijos de medios hermanos) varió de 6 a 40 personas (media: 15,3 personas). La mitad de las familias participantes tenían entre 11 y 18 miembros. El número promedio de hermanos y medios hermanos por familia fue de 8,7 y 3,0 , respectivamente.

El mayor número de casos de linfedema entre los 53 enfermos que tenían alguna relación con los casos índice se encontró entre los padres (42\%), se- guidos de los hermanos (25\%), hijos (17\%) y medios hermanos (13\%). Solo $4 \%$ de los cónyuges de los casos índice tenían linfedema.

La prevalencia de linfedema en los familiares de los casos índice fue de 2,4\%, ligeramente superior a la notificada para la población en general (1-2\%). Se encontraron las mayores prevalencias en los padres y hermanos de los casos índice $(6,4 \%$ y $2,1 \%$, respectivamente). Se observó una relación inversa proporcional entre la prevalencia de linfedema y el grado de parentesco entre los pacientes estudiados y los casos índice, pero dicha relación no fue estadísticamente significativa $(P=0,31$, según la prueba exacta de tendencia de dos colas). Cuando se comparó la prevalencia de linfedema en parientes de los casos índice, según su grado de parentesco, con la observada en las personas sin ninguna consanguinidad con ellos, solo resultó significativamente mayor la prevalencia de linfedema en los padres $(P=0,001)$.

De los 53 casos con linfedema relacionados con los casos índice, 28 pertenecían a familias integradas por 11 a 20 personas. Este fue el tamaño familiar más frecuente, aunque no el mayor. La proporción de los casos de linfedema dentro de una misma familia permaneció inalterada, independientemente del número de miembros que tuviera.

Este es el primer estudio genealógico en que se investigan los factores genéticos y de otra índole asociados con el linfedema producido por filarias y en que se analiza el grado de agregación familiar de esta enfermedad en una extensa comunidad endémica.

La diferencia observada en la proporción de casos con linfedema entre padres y cónyuges de los casos índice podría atribuirse a las diferencias genéticas entre ellos, dando por sentado que la distribución de edad y los factores ambientales que determinan la exposición al vector fueron similares en todos los miembros de la generación de mayor edad. (Cuenco KT, Halloran ME, Louis-Charles J, Lammie PJ. A family study of lymphedema of the leg in a lymphatic filariasis-endemic area. Am J Trop Med Hyg. 2004;70(2):180-4.)

\section{Valor pronóstico de la automedición de la tensión arterial frente a su medición ambulatoria en el consultorio}

Según un metaanálisis de los datos individuales de casi un millón de adultos que participaron en 61 estu- 